\title{
Maximization of Transfer Ratio and Minimization of Harmonics in Three Phase AC/AC Matrix Converter
}

\author{
Raheel Muzzammel ${ }^{1^{*}}$ and Umair Tahir ${ }^{1}$ \\ ${ }^{1}$ Department of Electrical Engineering, University of Lahore, Lahore, Pakistan.
}

Authors' contributions

This work was carried out in collaboration between both authors. Both authors read and approved the final manuscript.

Article Information

DOI: 10.9734/BJAST/2017/33416

Editor(s):

(1) Rodolfo Dufo Lopez, Electrical Engineering Department, University of Zaragoza, Spain.

Reviewers:

(1) Prashant Kumar, SPPU, India.

(2) O. V. Singh, Gautam Buddha University, Greater Noida, India.

(3) Liang Yang, Tianjin University, China.

(4) Derick Mathew, VIT University, Vellore, Tamil Nadu, India.

(5) Wen-Yeau Chang, St. Johns University, Taiwan.

Complete Peer review History: http://www.sciencedomain.org/review-history/19212

Original Research Article

Received: $14^{\text {th }}$ April 2017

Accepted: $16^{\text {th }}$ May 2017

Published: $26^{\text {th }}$ May 2017

\section{Abstract}

Energy saving and different working voltage applications are widely employing matrix converters. Matrix converters are used to convert three phase AC input voltages to three phase AC output voltages of required magnitude and frequency. Pulse width modulation is a technique used for converting three phase $A C$ input to three phase $A C$ output. In this research paper, pulse width modulation based matrix converter will be designed to acquire voltage of desired magnitude and frequency. Voltage transfer ratio will be maximized in this technique so that any desired voltage magnitude could be achieved. Secondly, harmonics will be made reduced in this design. Simulations will be performed in Matlab and characteristics of output waveform will be observed with respect to characteristics of input waveforms.

Keywords: Matrix converters; pulse width modulation; voltage transfer ratio; harmonics; matlab.

\footnotetext{
*Corresponding author: E-mail: raheelmuzzammel@gmail.com;
} 


\section{INTRODUCTION}

Energy saving and different working voltage applications are widely employing matrix converters. Matrix converters are used to convert three phase $A C$ input voltages to three phase $A C$ output voltages of required magnitude and frequency [1, 2]. In matrix converter, the basic component is a bidirectional switch. This switch works in a controlled way to generate a variable desired frequency. The control operation of switch makes it possible to work at high frequency that will enable to attain desired voltage. There is no intermediate DC link existing in the matrix converter. The complexity of modulation technique can be reduced by reducing the components in matrix converters according to requirement $[3,4,5,6,7,8]$.

Pulse width modulation is a technique used to generate pulsating signal of variable width so that a message or a signal could be encoded $[8,9,10]$. One of the most significant usage of this modulation scheme is to control the on/ off operation of the switching devices connected between the load and source when it is required to do so. In this way, not only power transfer is controlled but also the voltage of desired amplitude can be achieved. Since operation of switching is performed at high frequency and high frequency switching leads to high switching losses due to generation of harmonics. Non linear loads connected to supply are also the source of harmonics. Not only the power system operation but also the power system quality is highly affected due to undesirable characteristics of harmonics. Harmonic elimination techniques are employed to eliminate low order harmonics $[11,12]$. Higher order harmonics are also made reduced with different techniques for efficient power system operation [13, 14, 15, 16, 17]. Different topologies of active and passive filters are also deployed to uproot harmonics in the system $[18,19,20]$.

Power switches like bipolar junction transistors (BJTs), metal oxide silicon field effect transistors (MOSFETs) and insulated gate bipolar junction transistors (IGBTs) have revolutionized the topologies of matrix converter [21]. Matrix converter was made in 1980 by Venturini and Alesia. They developed a converter comprising of bidirectional switches and direct transfer function approach was developed as a modulation scheme for converter. Desired output voltages are obtained by the product of input voltages and modulation matrix [10, 22, 23]. In 1983, Rodriguez developed a fictitious DC link technique for matrix converter. In this technique, the switching of output occurs between the most positive input line and the most negative input line. This technique was further named as indirect transfer function approach [24, 25].

In 1983, Braun and in 1985, Kastner and Rodriguez developed the control method of matrix converter [26, 27]. However, Huber was the first man who published the space modulation scheme for matrix converter as a controlling scheme in 1989 [28]. High spikes of voltage and current should be avoided because these spikes may damage the semi-conductor switches based matrix converter. In 1992, it was experimentally proven by Schauder and Neft that bidirectional switches were the source of high quality of input and output current [29]. However, with the advancement in technology, this problem is resolved with the invention of microprocessor based converter controllers.

In this research paper, pulse width modulation based matrix converter will be designed to acquire voltage of desired magnitude and frequency. Voltage transfer ratio will be maximized in this technique so that any desired voltage magnitude could be achieved. Secondly, harmonics will be made reduced in this design. Simulations will be performed in Matlab and characteristics of output waveform will be observed with respect to characteristics of input waveform.

This research paper consists of following sections. Section II consists of Matrix Converters. Pulse width modulation is described mathematically in section III. Section IV consists of Matlab / Simulink implementation of PWM based matrix converter. Section $V$ comprises of conclusion.

\section{MATRIX CONVERTERS}

Matrix converter is employed to alter the frequency of input supply. It consists of a 
bidirectional switches which connect any output phase to any of the three phase input supply. In this research, a direct approach of converting $A C$ to $A C$ is used without the involvement of an intermediate DC link capacitor $[3,4,5]$. It has three phase input supply voltages. $V_{\alpha o}, V_{\beta}$ and $V_{\gamma_{o}}$ are the three phase output voltages. Nine elements of matrix are mathematically derived from the values of nine bidirectional switches i.e., $S_{11}$ to $S_{33}$. The three phase input connected to converter is given by (2.1), (2.2) and (2.3).

$$
\begin{gathered}
V_{\alpha i}=V_{i} \cos \left(\omega_{i} t\right) \\
V_{\beta i}=V_{i} \cos \left(\omega_{i} t+\frac{2 \pi}{3}\right) \\
V_{\gamma i}=V_{i} \cos \left(\omega_{i} t+\frac{4 \pi}{3}\right)
\end{gathered}
$$

and the required three phase output voltages from converter is given by (2.4), (2.5) and (2.6).

$$
\begin{gathered}
V_{\alpha o}=V_{o} \cos \left(\omega_{o} t\right) \\
V_{\beta o}=V_{o} \cos \left(\omega_{o} t+\frac{2 \pi}{3}\right) \\
V_{\gamma o}=V_{o} \cos \left(\omega_{o} t+\frac{4 \pi}{3}\right)
\end{gathered}
$$

The three phase input to converter is related to the three phase output of converter by the (2.7).

$$
\left[\begin{array}{l}
V_{\alpha o}(t) \\
V_{\beta o}(t) \\
V_{\gamma o}(t)
\end{array}\right]=\left[\begin{array}{lll}
M_{11} & M_{12} & M_{13} \\
M_{21} & M_{22} & M_{23} \\
M_{31} & M_{32} & M_{33}
\end{array}\right]\left[\begin{array}{l}
V_{\alpha i}(t) \\
V_{\beta i}(t) \\
V_{\gamma i}(t)
\end{array}\right]
$$

where $M_{11}$ to $M_{33}$ are the duty cycles of the switches $S_{11}$ to $S_{33}$.

Voltage source is usually used to feed the matrix converter and switching operation is done in such a way so as to avoid short circuiting of input terminals and open circuiting of the output terminals.

\section{PULSE WIDTH MODULATION}

Pulse width modulation is a technique used to generate pulsating signal of variable width so that a message or a signal could be encoded $[9,8]$. One of the most significant usage of this modulation scheme is to control the on/ off operation of the switching devices connected between the load and source when it is required to do so. Switching losses is negligible by using pulse width modulation because of very short transition intervals.

\subsection{Modulation Algorithm}

Assuming that the switches are ideal, i.e no losses occurs in switches.

The three phase input supply is given by (3.1).

$$
\left[\begin{array}{l}
V_{\alpha i}(t) \\
V_{\beta i}(t) \\
V_{\gamma i}(t)
\end{array}\right]=\left[\begin{array}{c}
\cos \left(\omega_{i} t\right) \\
\cos \left(\omega_{i} t+\frac{2 \pi}{3}\right) \\
\cos \left(\omega_{i} t+\frac{4 \pi}{3}\right)
\end{array}\right] \times V_{i}
$$

$T_{s}$ is the switching time sequence after which switching operation is done and is reciprocal to $f_{s}$. The switching time $T_{s}$ is given by (3.2).

$$
T_{s}=t_{\alpha_{i} \alpha_{o}}+t_{\beta_{i} \alpha_{o}}+t_{\gamma_{i} \alpha_{o}}=t_{\alpha_{i} \beta_{o}}+t_{\beta_{i} \beta_{o}}+t_{\gamma_{i} \beta_{o}}=t_{\alpha_{i} \gamma_{o}}+t_{\beta_{i} \gamma_{o}}+t_{\gamma_{i} \gamma_{o}}=\frac{1}{f_{s}}
$$

The length of sequences are same which means that switching frequency $f_{s}$ for all the sequences is same.

The three phase output voltages are displaced from each other by an angle of $120^{\circ}$ and are given in terms of switching time in (3.3), (3.4) and (3.5).

$$
\begin{aligned}
& V_{\alpha o}(t)=V_{i} \cos (\omega t) \frac{t_{\alpha_{i} \alpha_{o}}}{T_{s}}+V_{i} \cos \left(\omega t+\frac{2 \pi}{3}\right) \frac{t_{\beta_{i} \alpha_{o}}}{T_{s}}+V_{i} \cos \left(\omega t+\frac{4 \pi}{3}\right) \frac{t_{\gamma_{i} \alpha_{o}}}{T_{s}} \\
& V_{\beta o}(t)=V_{i} \cos (\omega t) \frac{t_{\alpha_{i} \beta_{o}}}{T_{s}}+V_{i} \cos \left(\omega t+\frac{2 \pi}{3}\right) \frac{t_{\beta_{i} \beta_{o}}}{T_{s}}+V_{i} \cos \left(\omega t+\frac{4 \pi}{3}\right) \frac{t_{\gamma_{i} \beta_{o}}}{T_{s}}
\end{aligned}
$$




$$
V_{\gamma o}(t)=V_{i} \cos (\omega t) \frac{t_{\alpha_{i} \gamma_{o}}}{T_{s}}+V_{i} \cos \left(\omega t+\frac{2 \pi}{3}\right) \frac{t_{\beta_{i} \gamma_{o}}}{T_{s}}+V_{i} \cos \left(\omega t+\frac{4 \pi}{3}\right) \frac{t_{\gamma_{i} \gamma_{o}}}{T_{s}}
$$

Now, modulating frequency $\omega_{m}$ is added in the input frequency $\omega_{i}$ if the input frequency $\omega_{i}$ is increased to $\omega_{o} . \omega_{o}=\omega_{i}+\omega_{m}$.

The switching sequences for $V_{o}$ at $0^{\circ}$ are given in (3.6), (3.7) and (3.8).

$$
\begin{gathered}
t_{\alpha_{i} \alpha_{o}}=\frac{T_{s}}{3}\left(1+2 q \cos \left(\omega_{m} t+\theta\right)\right) \\
t_{\beta_{i} \alpha_{o}}=\frac{T_{s}}{3}\left(1+2 q \cos \left(\omega_{m} t+\theta-\frac{2 \pi}{3}\right)\right) \\
t_{\gamma_{i} \alpha_{o}}=\frac{T_{s}}{3}\left(1+2 q \cos \left(\omega_{m} t+\theta-\frac{4 \pi}{3}\right)\right)
\end{gathered}
$$

The switching sequences for $V_{o}$ at $120^{\circ}$ are given in (3.9), (3.10) and (3.11).

$$
\begin{gathered}
t_{\alpha_{i} \beta_{o}}=\frac{T_{s}}{3}\left(1+2 q \cos \left(\omega_{m} t+\theta-\frac{4 \pi}{3}\right)\right) \\
t_{\beta_{i} \beta_{o}}=\frac{T_{s}}{3}\left(1+2 q \cos \left(\omega_{m} t+\theta\right)\right) \\
t_{\gamma_{o} \beta_{o}}=\frac{T_{s}}{3}\left(1+2 q \cos \left(\omega_{m} t+\theta-\frac{2 \pi}{3}\right)\right)
\end{gathered}
$$

The switching sequences for $V_{o}$ at $240^{\circ}$ are given in (3.12), (3.13) and (3.14).

$$
\begin{gathered}
t_{\alpha_{i} \gamma_{o}}=\frac{T_{s}}{3}\left(1+2 q \cos \left(\omega_{m} t+\theta-\frac{2 \pi}{3}\right)\right) \\
t_{\beta_{i} \gamma_{o}}=\frac{T_{s}}{3}\left(1+2 q \cos \left(\omega_{m} t+\theta-\frac{4 \pi}{3}\right)\right) \\
t_{\gamma_{i} \gamma_{o}}=\frac{T_{s}}{3}\left(1+2 q \cos \left(\omega_{m} t+\theta\right)\right)
\end{gathered}
$$

Modulation matrices are given in (3.15) and (3.16).

$$
\begin{aligned}
& {\left[M_{1}(t)\right]=\frac{1}{3}\left[\begin{array}{ccc}
1+2 q \cos \left(\omega_{m} t\right) & 1+2 q \cos \left(\omega_{m} t-\frac{2 \pi}{3}\right) & 1+2 q \cos \left(\omega_{m} t-\frac{4 \pi}{3}\right) \\
1+2 q \cos \left(\omega_{m} t-\frac{4 \pi}{3}\right) & 1+2 q \cos \left(\omega_{m} t\right) & 1+2 q \cos \left(\omega_{m} t-\frac{2 \pi}{3}\right) \\
1+2 q \cos \left(\omega_{m} t-\frac{2 \pi}{3}\right) & 1+2 q \cos \left(\omega_{m} t-\frac{4 \pi}{3}\right) & 1+2 q \cos \left(\omega_{m} t\right)
\end{array}\right]} \\
& \text { with } \omega_{m}=\left(\omega_{0}-\omega_{i}\right) . \\
& \left.\qquad M_{2}(t)\right]=\frac{1}{3}\left[\begin{array}{ccc}
1+2 q \cos \left(\omega_{m} t\right) & 1+2 q \cos \left(\omega_{m} t-\frac{2 \pi}{3}\right) & 1+2 q \cos \left(\omega_{m} t-\frac{4 \pi}{3}\right) \\
1+2 q \cos \left(\omega_{m} t-\frac{2 \pi}{3}\right) & 1+2 q \cos \left(\omega_{m} t-\frac{4 \pi}{3}\right) & 1+2 q \cos \left(\omega_{m} t\right) \\
1+2 q \cos \left(\omega_{m} t-\frac{4 \pi}{3}\right) & 1+2 q \cos \left(\omega_{m} t\right) & 1+2 q \cos \left(\omega_{m} t-\frac{2 \pi}{3}\right)
\end{array}\right]
\end{aligned}
$$

with $\omega_{m}=-\left(\omega_{0}+\omega_{i}\right)$. Sum of $M_{1}(t)$ and $M_{2}(t)$ is required for the cancellation of phase displacement effect and is given in (3.17) and (3.18).

$$
[M(t)]=\left[M_{1}(t)\right]+\left[M_{2}(t)\right]
$$




$$
\begin{aligned}
& {[M(t)]=} \frac{1}{3}\left[\begin{array}{ccc}
1+2 q \cos \left(\omega_{m} t\right) & 1+2 q \cos \left(\omega_{m} t-\frac{2 \pi}{3}\right) & 1+2 q \cos \left(\omega_{m} t-\frac{4 \pi}{3}\right) \\
1+2 q \cos \left(\omega_{m} t-\frac{4 \pi}{3}\right) & 1+2 q \cos \left(\omega_{m} t\right) & 1+2 q \cos \left(\omega_{m} t-\frac{2 \pi}{3}\right) \\
1+2 q \cos \left(\omega_{m} t-\frac{2 \pi}{3}\right) & 1+2 q \cos \left(\omega_{m} t-\frac{4 \pi}{3}\right) & 1+2 q \cos \left(\omega_{m} t\right)
\end{array}\right] \\
&+\frac{1}{3}\left[\begin{array}{ccc}
1+2 q \cos \left(\omega_{m} t\right) & 1+2 q \cos \left(\omega_{m} t-\frac{2 \pi}{3}\right) & 1+2 q \cos \left(\omega_{m} t-\frac{4 \pi}{3}\right) \\
1+2 q \cos \left(\omega_{m} t-\frac{2 \pi}{3}\right) & 1+2 q \cos \left(\omega_{m} t-\frac{4 \pi}{3}\right) & 1+2 q \cos \left(\omega_{m} t\right) \\
1+2 q \cos \left(\omega_{m} t-\frac{4 \pi}{3}\right) & 1+2 q \cos \left(\omega_{m} t\right) & 1+2 q \cos \left(\omega_{m} t-\frac{2 \pi}{3}\right)
\end{array}\right]
\end{aligned}
$$

The output voltage is given by (3.19) and (3.20).

$$
\begin{gathered}
V_{o}(t)=M(t) \cdot V_{i}(t) \\
{\left[V_{o}(t)\right]=\frac{1}{3}\left[\begin{array}{ccc}
1+2 q \cos \left(\omega_{m} t\right) & 1+2 q \cos \left(\omega_{m} t-\frac{2 \pi}{3}\right) & 1+2 q \cos \left(\omega_{m} t-\frac{4 \pi}{3}\right) \\
1+2 q \cos \left(\omega_{m} t-\frac{4 \pi}{3}\right) & 1+2 q \cos \left(\omega_{m} t\right) & 1+2 q \cos \left(\omega_{m} t-\frac{2 \pi}{3}\right) \\
1+2 q \cos \left(\omega_{m} t-\frac{2 \pi}{3}\right) & 1+2 q \cos \left(\omega_{m} t-\frac{4 \pi}{3}\right) & 1+2 q \cos \left(\omega_{m} t\right)
\end{array}\right]} \\
+\frac{1}{3}\left[\begin{array}{ccc}
1+2 q \cos \left(\omega_{m} t\right) & 1+2 q \cos \left(\omega_{m} t-\frac{2 \pi}{3}\right) & 1+2 q \cos \left(\omega_{m} t-\frac{4 \pi}{3}\right) \\
1+2 q \cos \left(\omega_{m} t-\frac{2 \pi}{3}\right) & 1+2 q \cos \left(\omega_{m} t-\frac{4 \pi}{3}\right) & 1+2 q \cos \left(\omega_{m} t\right) \\
1+2 q \cos \left(\omega_{m} t-\frac{4 \pi}{3}\right) & 1+2 q \cos \left(\omega_{m} t\right) & 1+2 q \cos \left(\omega_{m} t-\frac{2 \pi}{3}\right)
\end{array}\right] \\
\times \quad\left[\begin{array}{c}
V_{i}\left(\omega_{m} t\right) \\
V_{i}\left(\omega_{m} t-\frac{2 \pi}{3}\right) \\
V_{i}\left(\omega_{m} t-\frac{2 \pi}{3}\right)
\end{array}\right]
\end{gathered}
$$

\section{MATLAB / SIMULINK IMPLEMENTATION}

Matlab/ Simulink is employed to develop the pulse width modulation based matrix converter. Initially, a three phase source is required whose amplitude and frequency can be changed by user. Matlab embedded function is used to design a three phase source have a phase difference of $120^{\circ}$ between two phases. A digital clock is used to design a sampling time for a three phase source. Matlab embedded modulation function block requires input voltages, input frequency to produce the required output voltages and output frequency. This block also develops the switching intervals for the nine bidirectional switches. PWM signal is generated by gate signal generator for nine bidirectional IGBT based switches. Each switch consists of two IGBTs. $s_{11}$ to $s_{33}$ are the gates for applying gate signals to bidirectional switches.
Simulations are performed on Matlab / Simulink to verify the model developed for pulse width modulation based matrix converter and is given in $1,2,3$. This model is tested for different scenarios to verify the fact that this model is maximizing the voltage transfer ratio and minimizing the harmonics.

\subsection{Modulation Block with fixed Input Frequency of $50 \mathrm{~Hz}$}

Input frequency of the system is made fixed i.e., at $50 \mathrm{~Hz}$. Output frequency is varied according to the requirement of load. Simulations are performed for this design setup and it is verified that any desired frequency can be achieved irrespective of input frequency and hence variable frequency loads can work smoothly without taking into consideration of input frequency and it is shown in 4,5,6,7,8,9,10. 


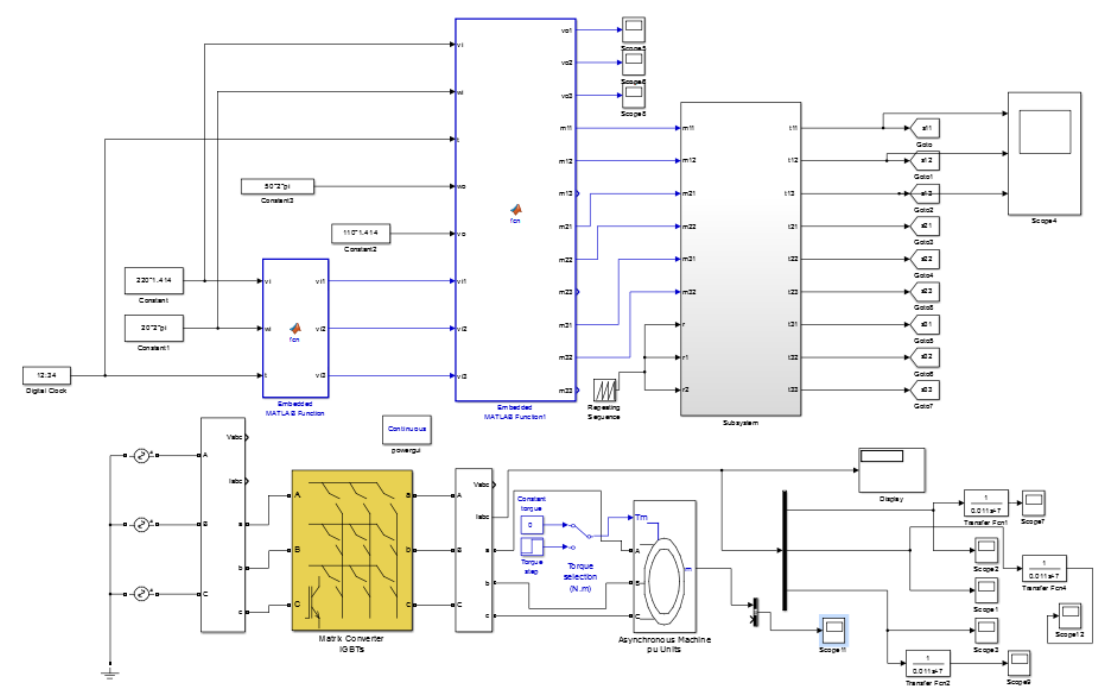

Fig. 1. Matlab/Simulink model of PWM based matrix converter

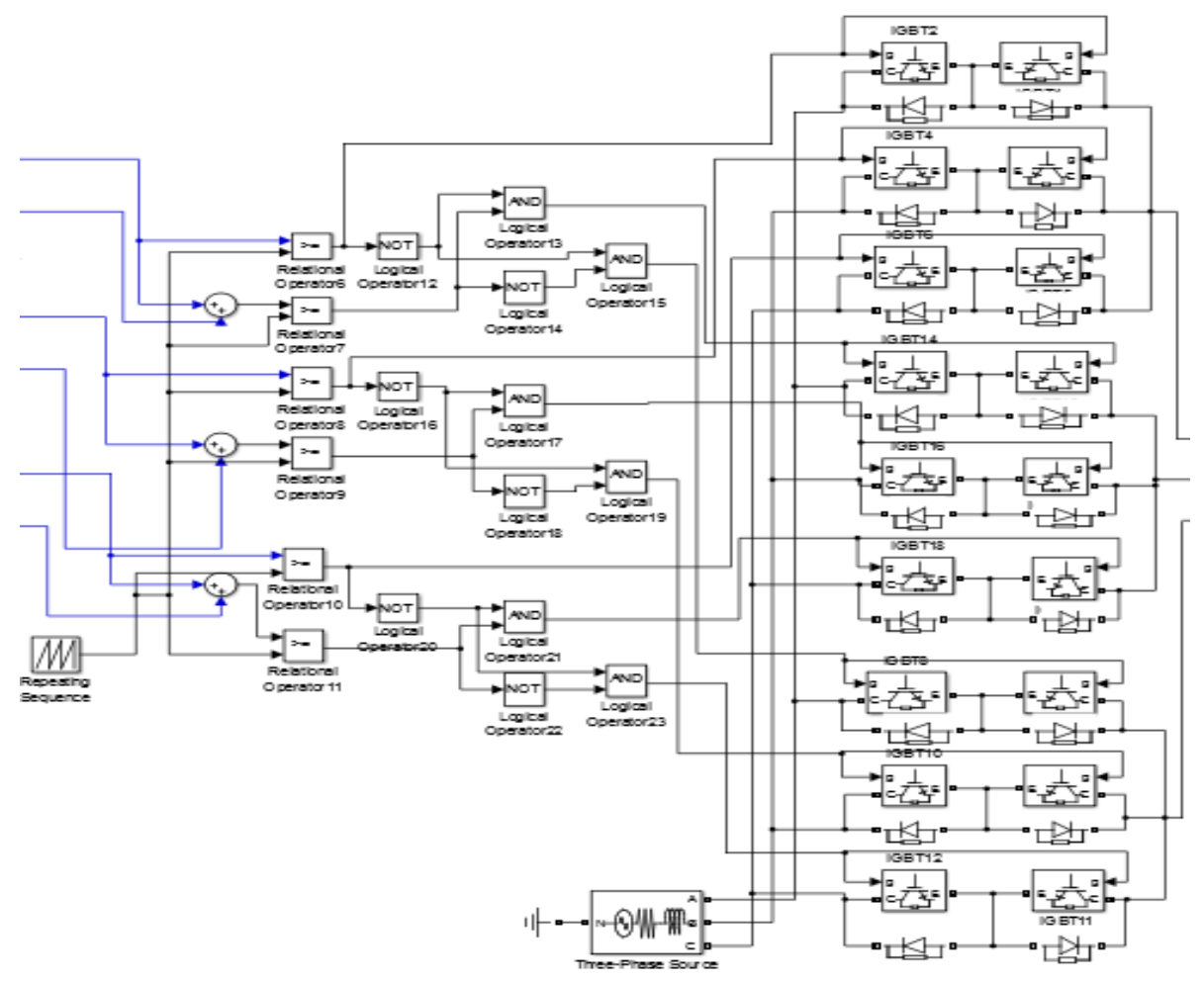

Fig. 2. Internal structure of matrix converters 


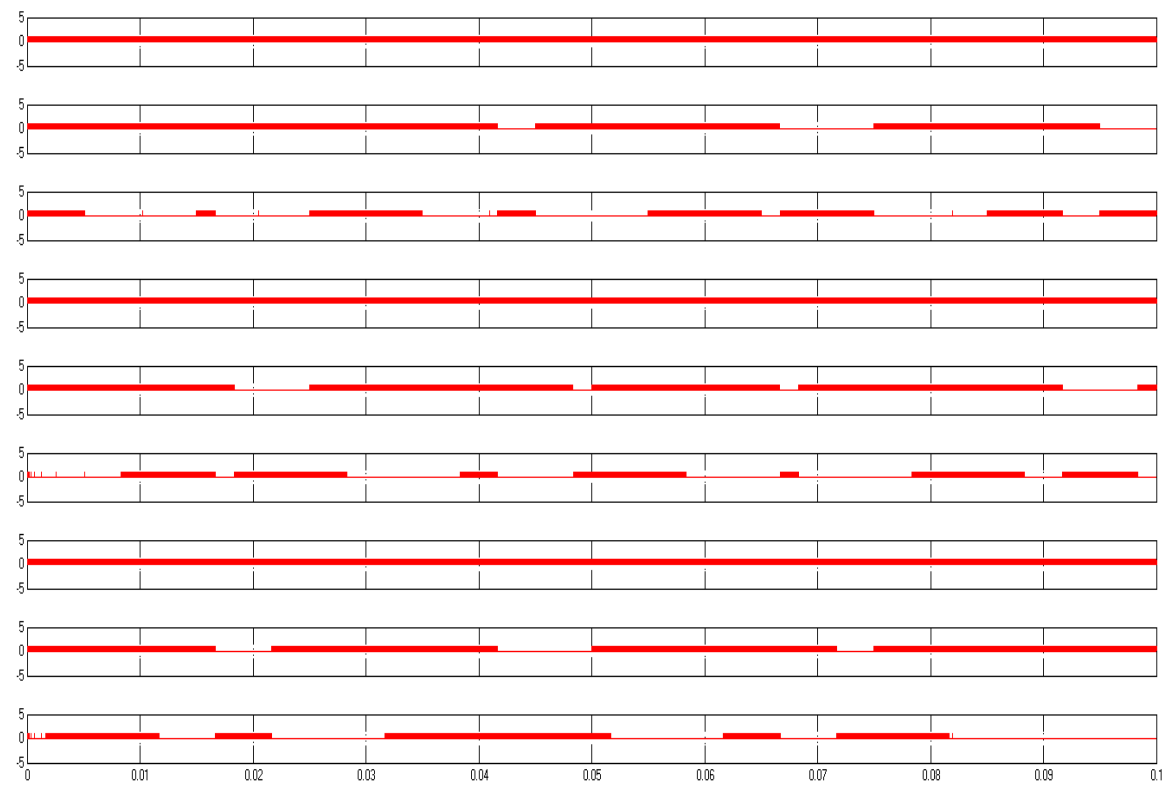

Fig. 3. Timing diagram of switches of matrix converters

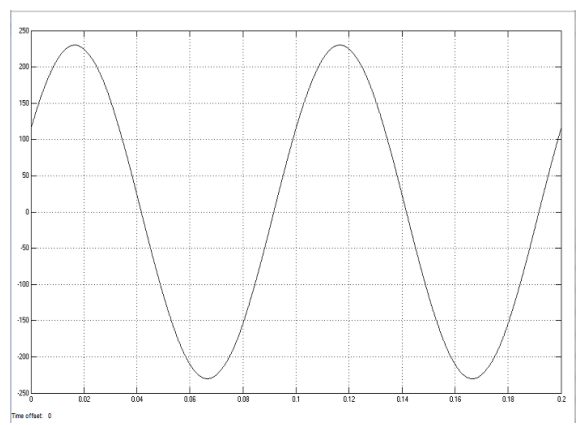

Fig. 4. $10 \mathrm{~Hz}$ output signal with $50 \mathrm{~Hz}$ input signal frequency

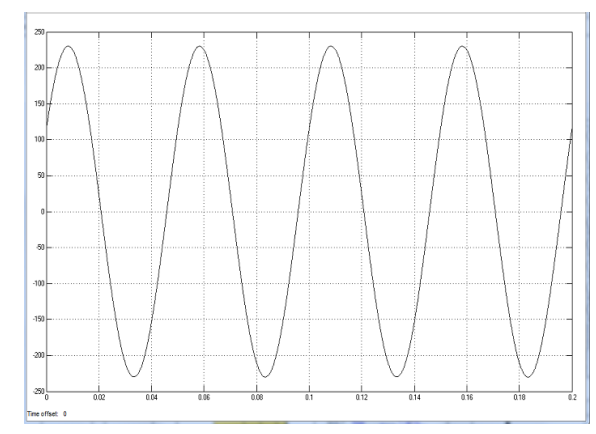

Fig. $5.20 \mathrm{~Hz}$ output signal with $50 \mathrm{~Hz}$ input signal frequency 


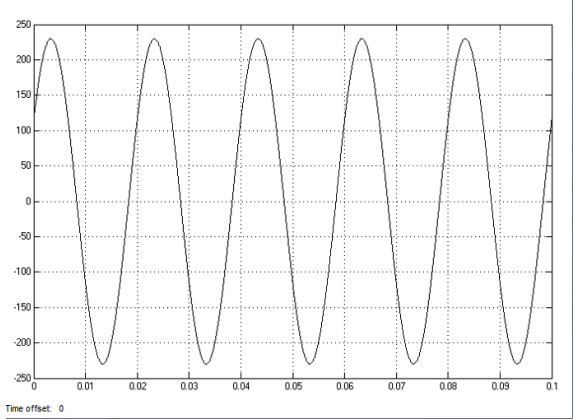

Fig. 6. $50 \mathrm{~Hz}$ output signal with $50 \mathrm{~Hz}$ input signal frequency

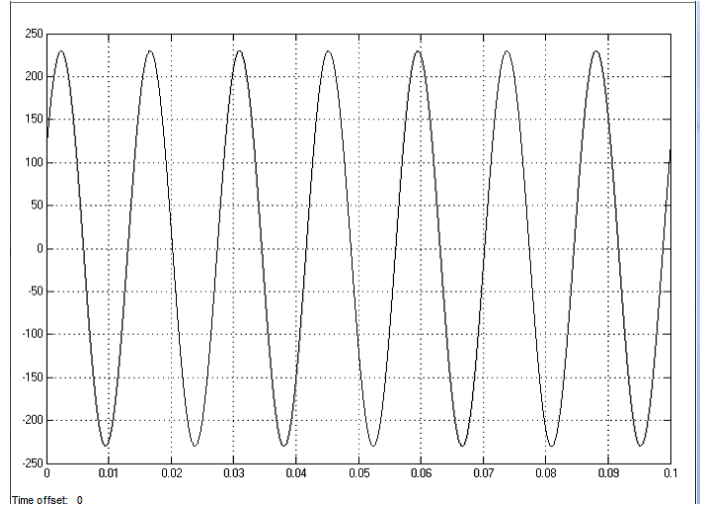

Fig. 7. $70 \mathrm{~Hz}$ output signal with $50 \mathrm{~Hz}$ input signal frequency

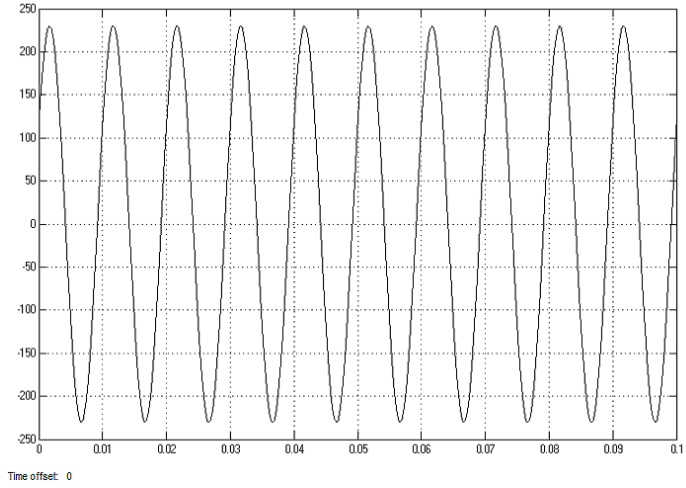

Fig. 8. $100 \mathrm{~Hz}$ output signal with $50 \mathrm{~Hz}$ input signal frequency 


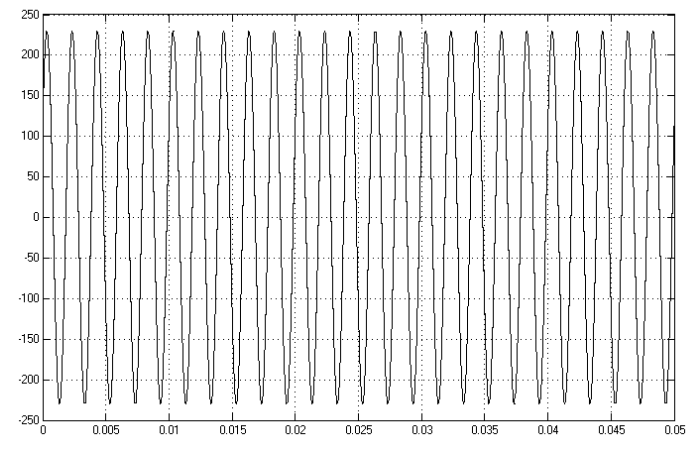

Fig. 9. $500 \mathrm{~Hz}$ output signal with $50 \mathrm{~Hz}$ input signal frequency

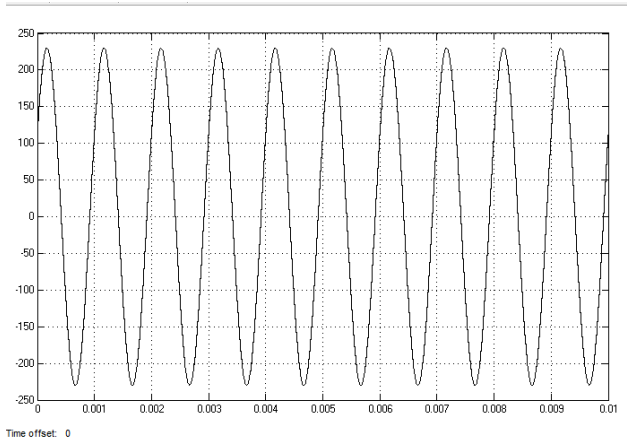

Fig. 10. $1000 \mathrm{~Hz}$ output signal with $50 \mathrm{~Hz}$ input signal frequency

\subsection{Modulation Block with fixed Output Frequency of $50 \mathrm{~Hz}$}

Output frequency of the system is made fixed i.e., at $50 \mathrm{~Hz}$. Input frequency is varied according to the requirement of sources. Simulations are performed for this design setup and it is verified that any desired input frequency can not affect output frequency and hence constant frequency loads can work smoothly without taking into consideration of input frequency and it is shown in $11,12,13,14,15,16,17$.
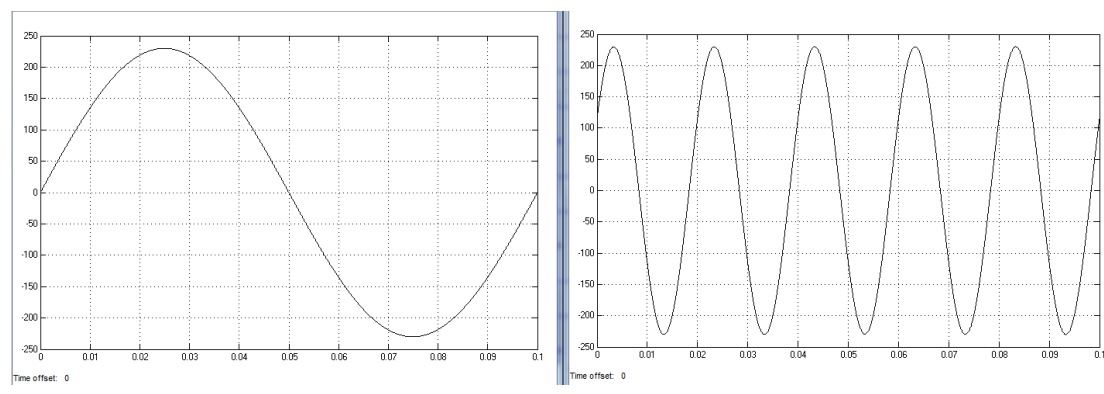

Fig. 11. $10 \mathrm{~Hz}$ input signal with $50 \mathrm{~Hz}$ output signal 


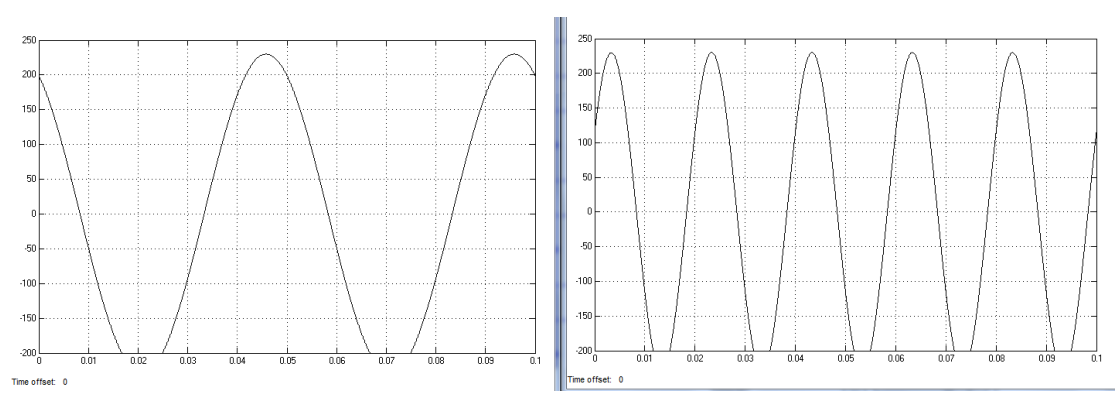

Fig. 12. $20 \mathrm{~Hz}$ Input Signal with $50 \mathrm{~Hz}$ Output Signal

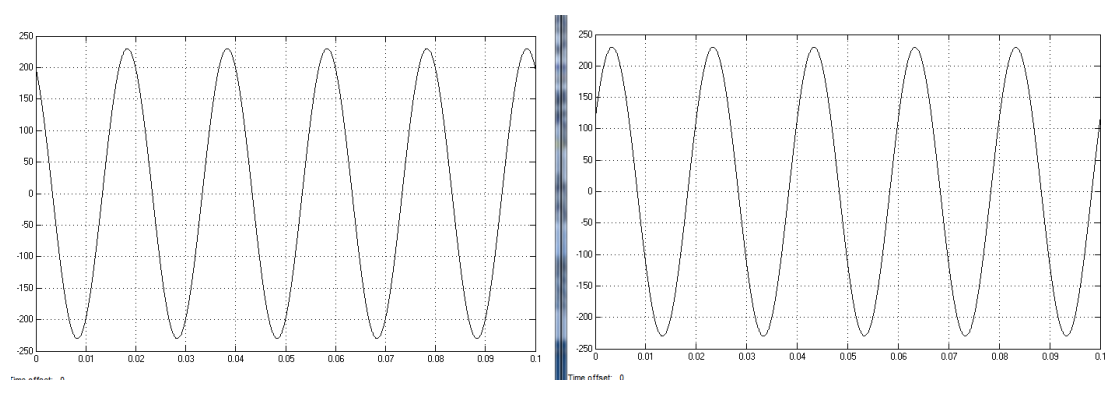

Fig. 13. $50 \mathrm{~Hz}$ input signal with $50 \mathrm{~Hz}$ output signal

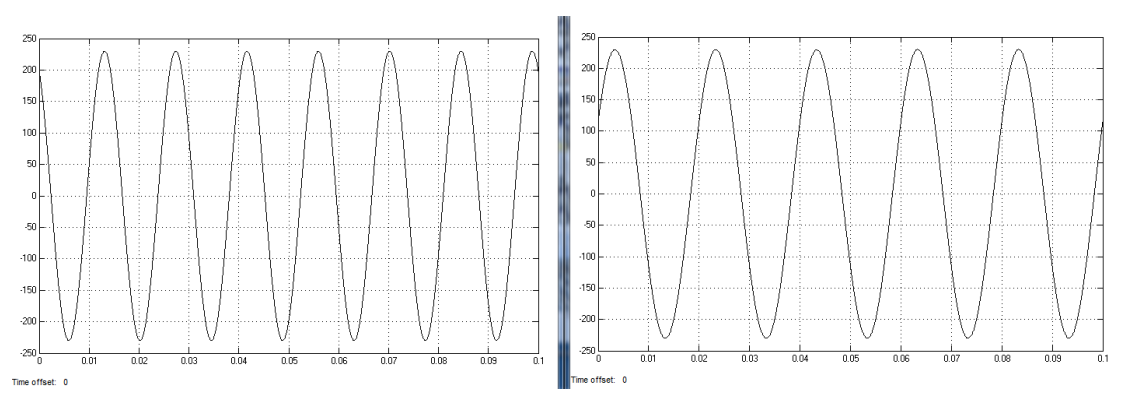

Fig. $14.70 \mathrm{~Hz}$ input signal with $50 \mathrm{~Hz}$ output signal

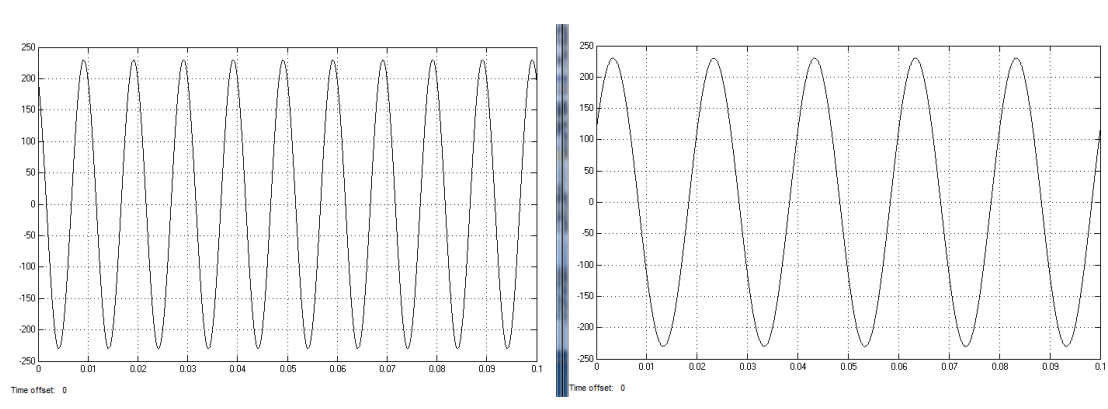

Fig. 15. $100 \mathrm{~Hz}$ input signal with $50 \mathrm{~Hz}$ output signal 


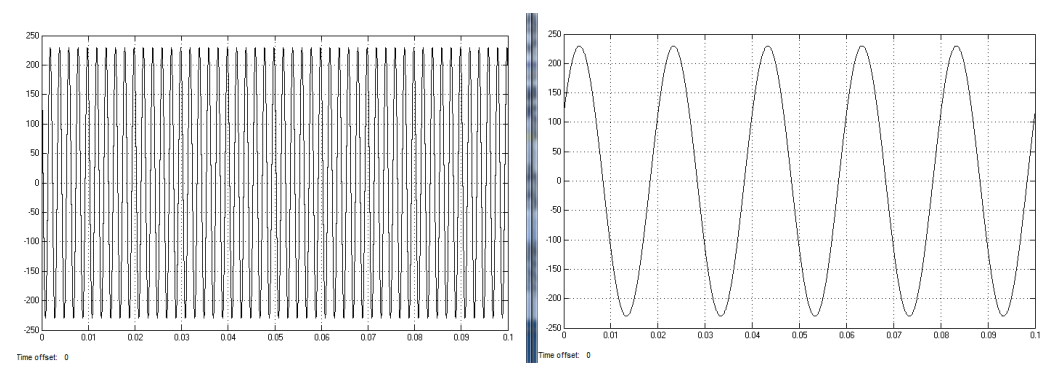

Fig. 16. $500 \mathrm{~Hz}$ input signal with $50 \mathrm{~Hz}$ output signal

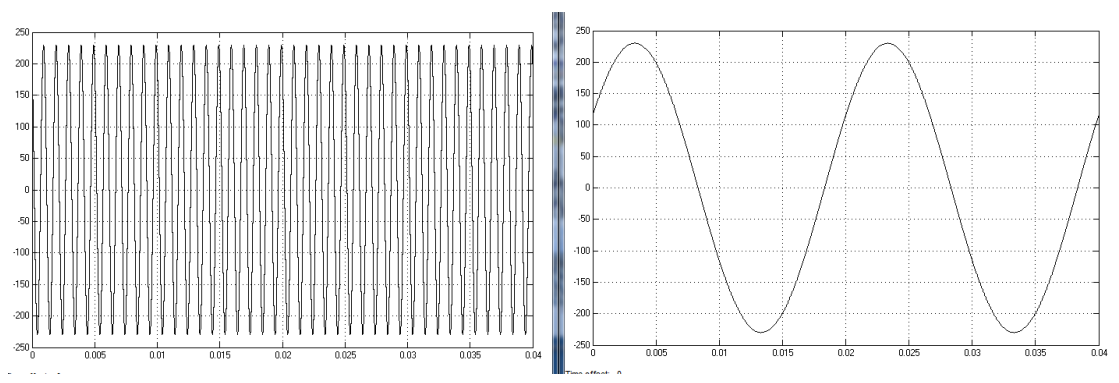

Fig. 17. $1000 \mathrm{~Hz}$ input signal with $50 \mathrm{~Hz}$ output signal

\subsection{Modulation Block with fixed Input Voltage of $220 \mathrm{~V}$}

Input voltage of the system is made fixed i.e., at $220 \mathrm{~V}$. Output voltage is made varied according to the load requirement. Simulations are carried out and it is verified that variable voltage based loads can work efficiently over any desired operating voltages and input voltage or source voltage has nothing to do with it. It is shown in $18,19,20$.

\subsection{Modulation Block With fixed Output Voltage of 220V}

Output voltage of the system is made fixed i.e., at $220 \mathrm{~V}$. Input voltage is made varied according to the load requirement. Simulations are carried out and it is verified that loads can work efficiently with any variable voltage source due to some unwanted reasons. Safety can be much ensured for sensitive loads which are usually shut down due to change in voltages. It is shown in $21,22,23$.

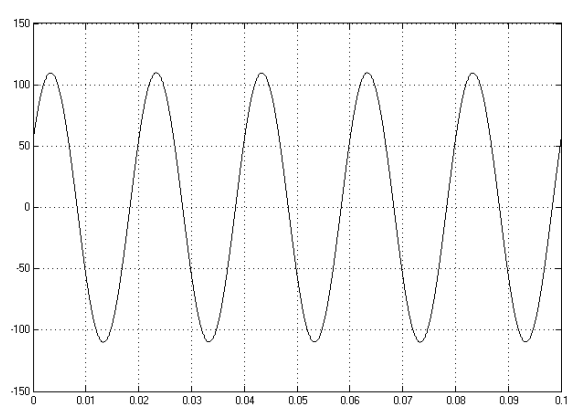

Fig. 18. $110 \mathrm{~V}$ output voltage with $220 \mathrm{~V}$ input voltage 


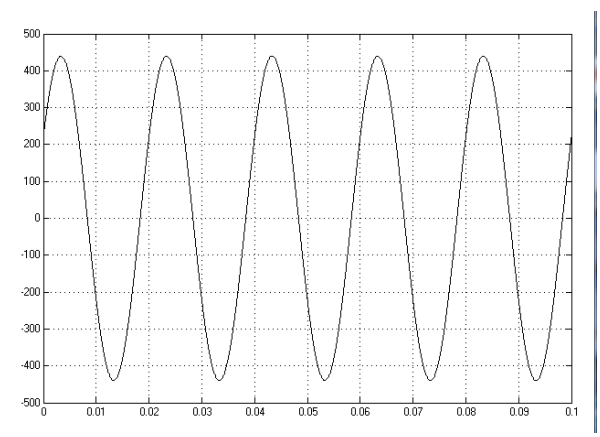

Fig. 19. $440 \mathrm{~V}$ output voltage with $220 \mathrm{~V}$ input voltage

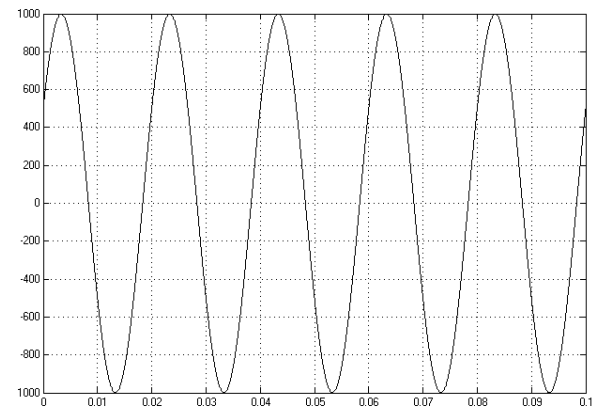

Fig. 20. $1000 \mathrm{~V}$ output voltage with $220 \mathrm{~V}$ input voltage

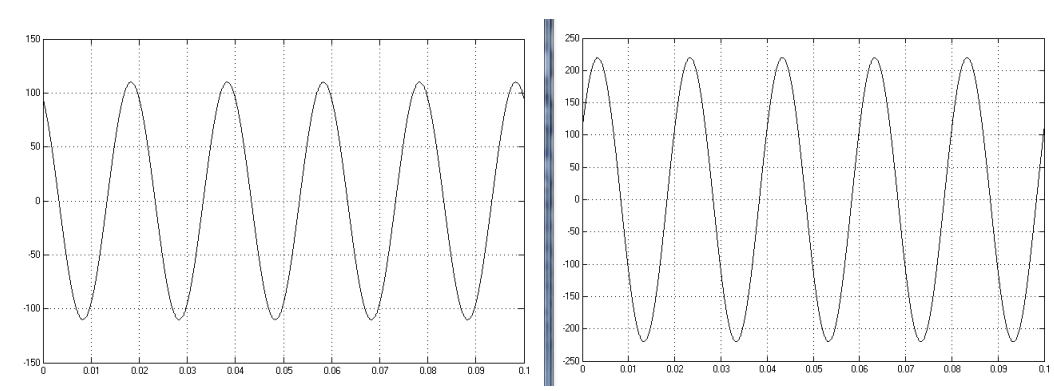

Fig. 21. 110V input voltage with $220 \mathrm{~V}$ output voltage

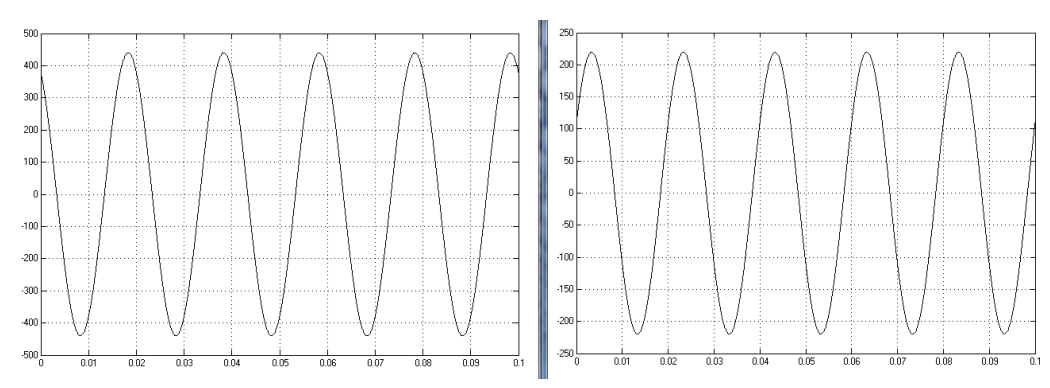

Fig. 22. $440 \mathrm{~V}$ input voltage with $220 \mathrm{~V}$ output voltage 

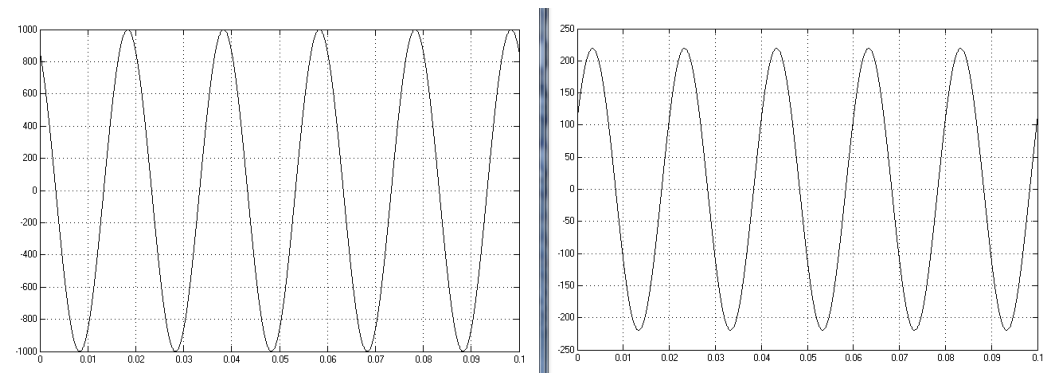

Fig. 23. $1000 \mathrm{~V}$ input voltage with $220 \mathrm{~V}$ output voltage

\subsection{Harmonic Analysis with fixed Input Frequency of $50 \mathrm{~Hz}$}

Input frequency of the system is made fixed i.e., at $50 \mathrm{~Hz}$. Output frequency is varied according to the requirement of load. Simulations are performed for this design setup and it is verified that any desired output frequency is achieved with less higher or lower order desired frequency components. In other words, any desired frequency can be attained with less harmonic losses. It is shown in $24,25,26,27,28,29$.

\subsection{Pulse Width Modulation with fixed Output Frequency of 50 $\mathrm{Hz}$}

Output frequency of the system is made fixed i.e., at $50 \mathrm{~Hz}$. Input frequency is varied. Simulations are performed for this design setup and it is verified that output frequency cannot be affected by change in input frequency due to unwanted reasons and output frequency can be made constant with less harmonic contents. It is shown in $30,31,32,33,34$.

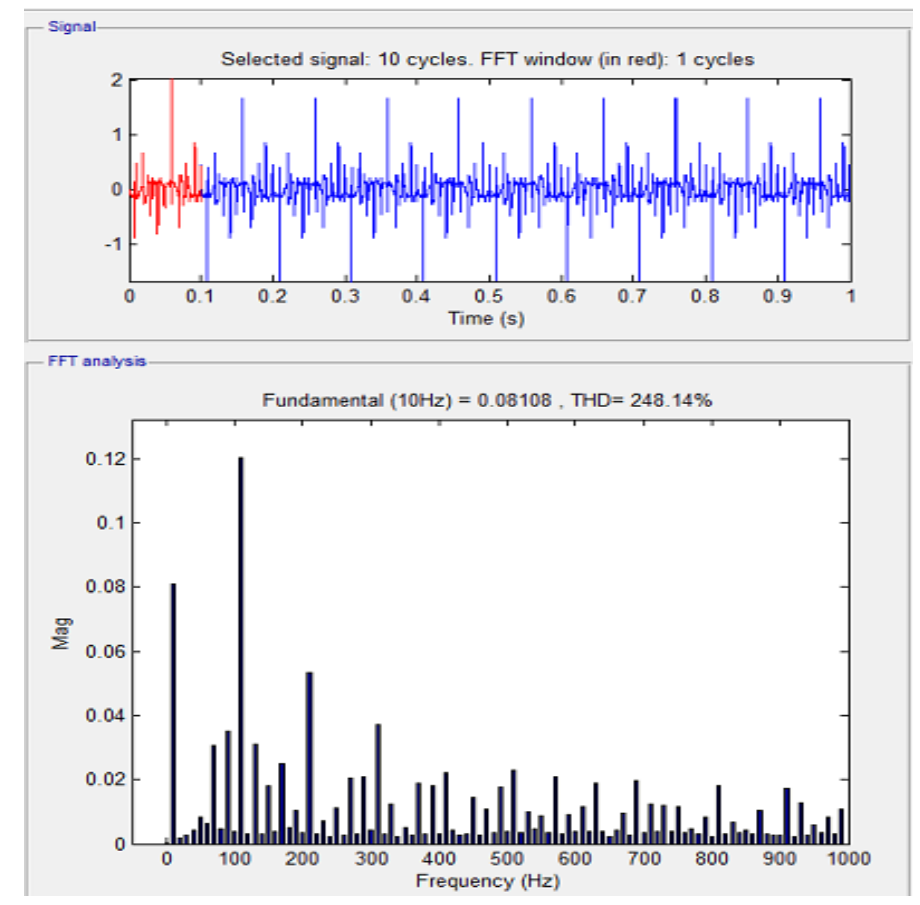

Fig. 24. FFT analysis of $10 \mathrm{~Hz}$ output signal with $50 \mathrm{~Hz}$ input signal 


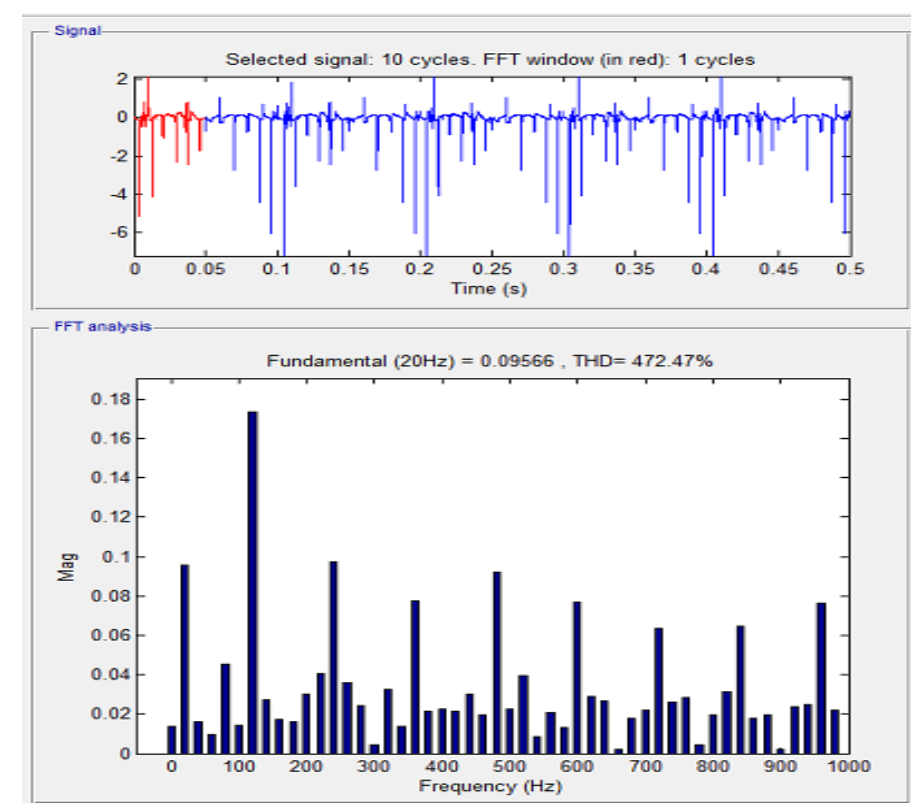

Fig. 25. FFT analysis of $20 \mathrm{~Hz}$ output signal with $50 \mathrm{~Hz}$ input signal

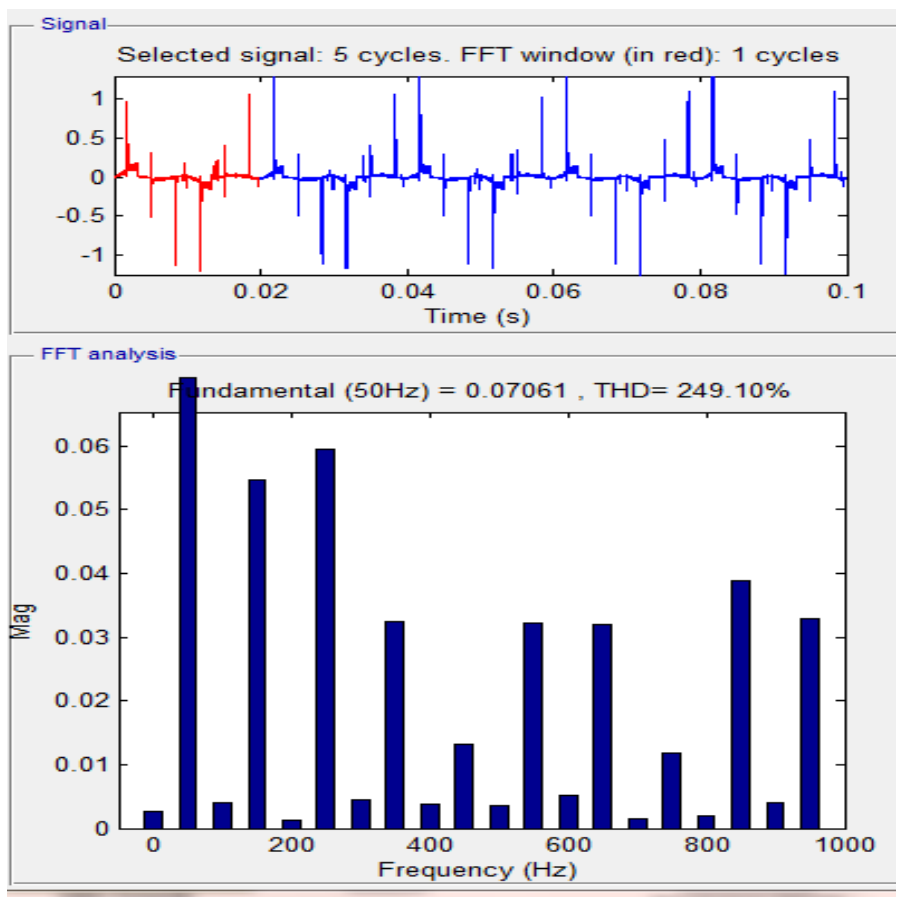

Fig. 26. FFT analysis of $50 \mathrm{~Hz}$ output signal with $50 \mathrm{~Hz}$ input signal 


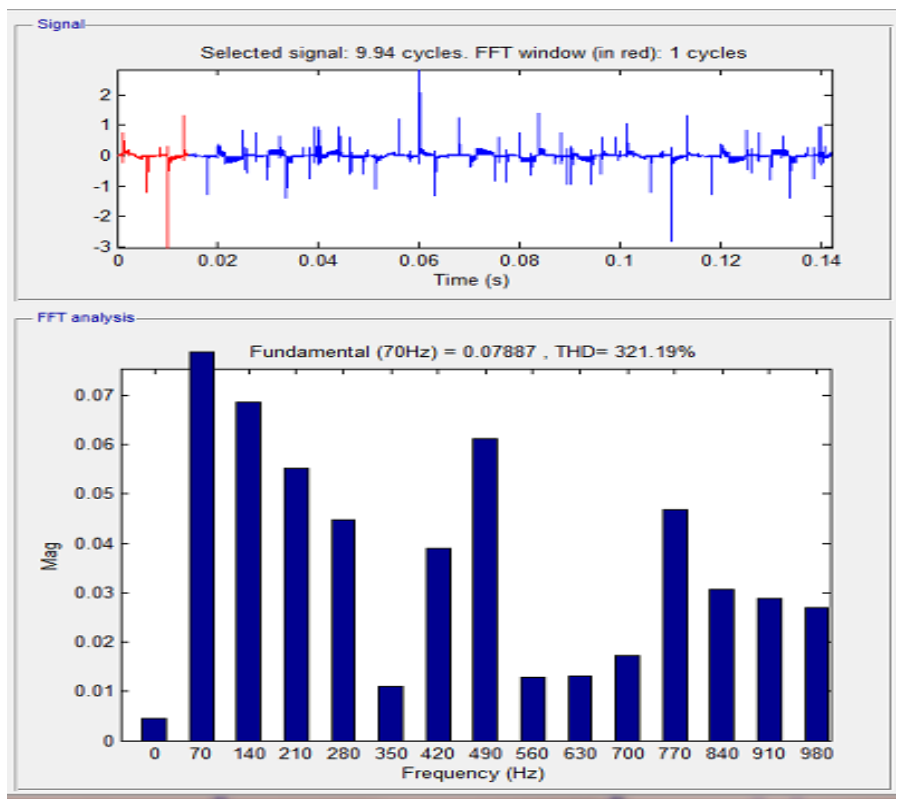

Fig. 27. FFT analysis of $70 \mathrm{~Hz}$ Output Signal with $50 \mathrm{~Hz}$ Input Signal

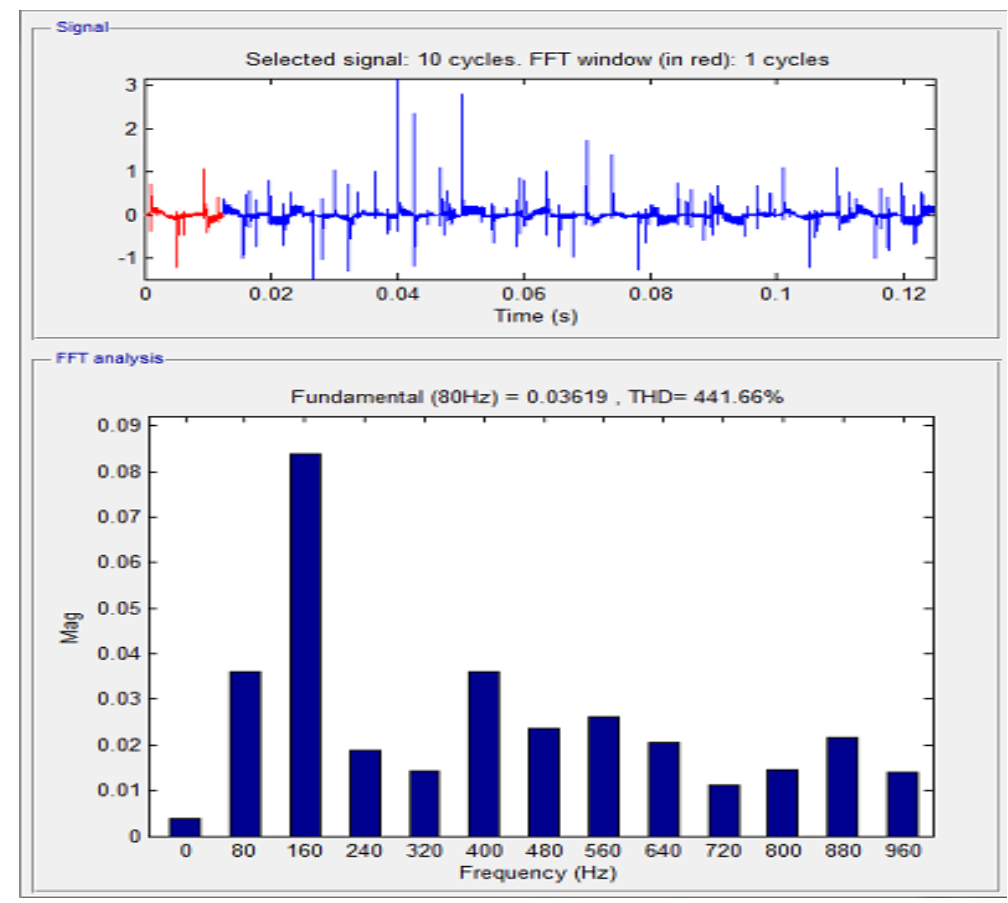

Fig. 28. FFT analysis of $80 \mathrm{~Hz}$ Output Signal with $50 \mathrm{~Hz}$ Input Signal 


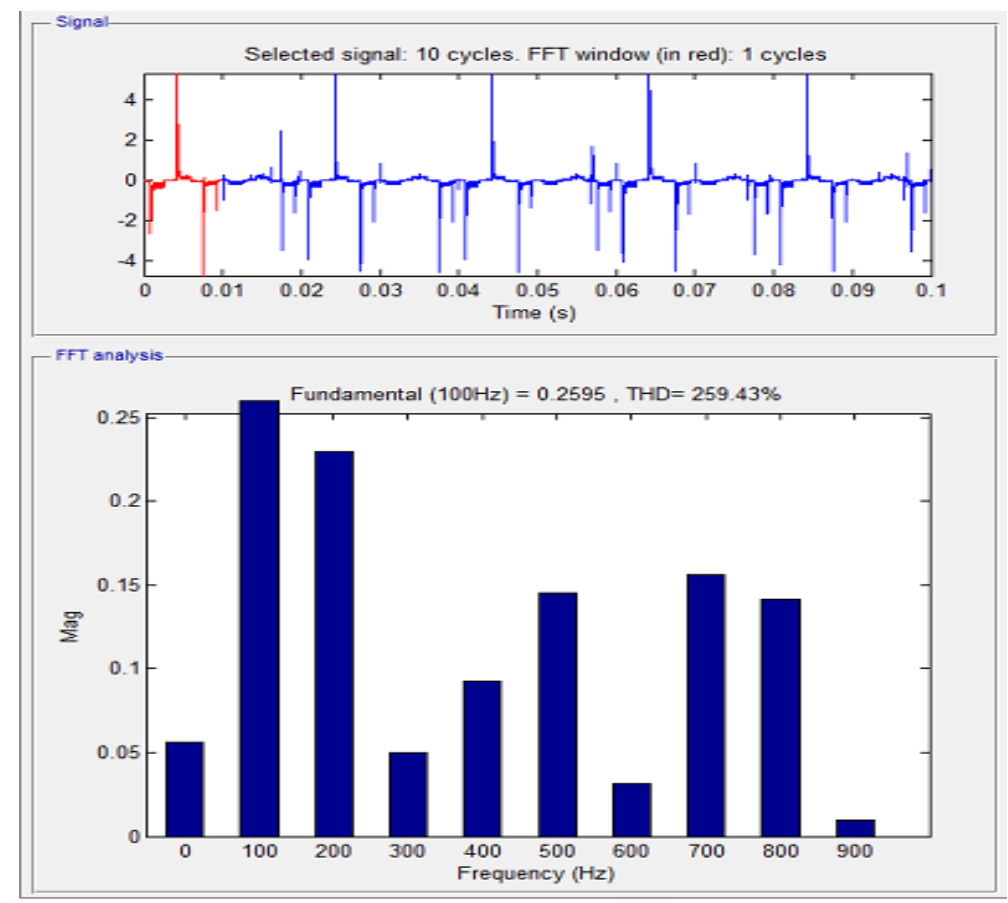

Fig. 29. FFT analysis of $100 \mathrm{~Hz}$ output signal with $50 \mathrm{~Hz}$ input signal

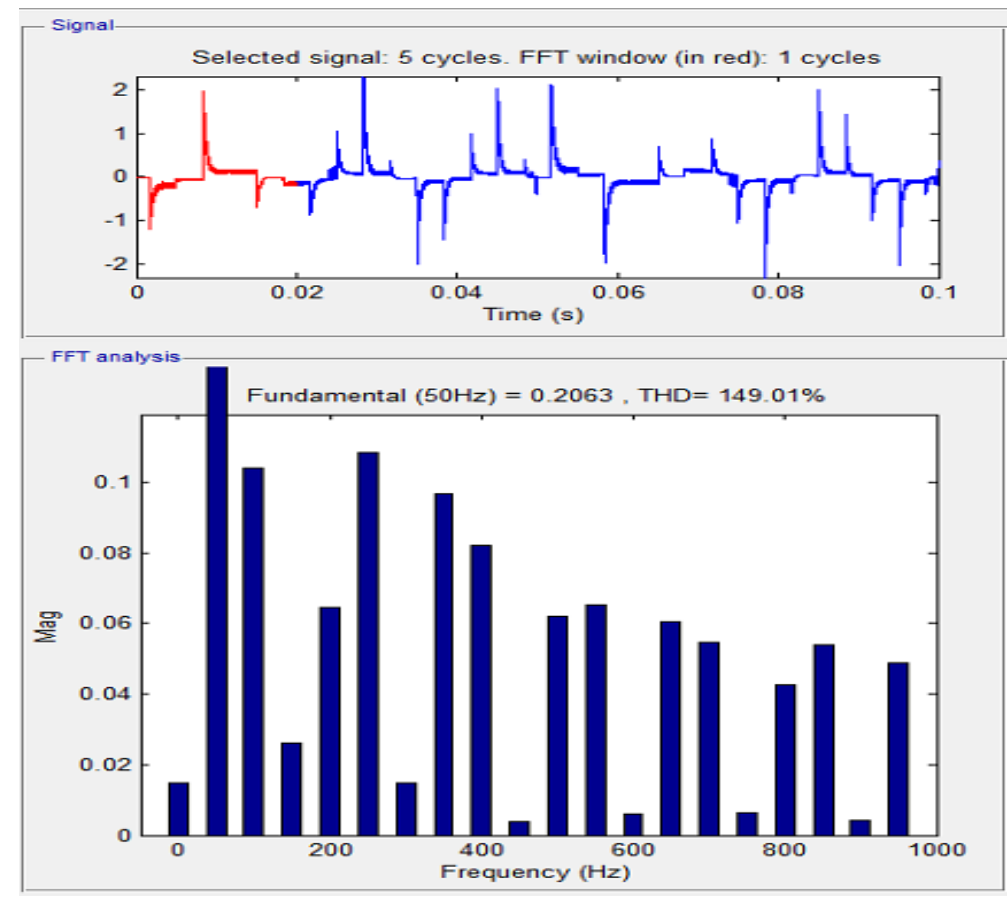

Fig. 30. FFT analysis of fixed output $50 \mathrm{~Hz}$ with $10 \mathrm{~Hz}$ input signal 

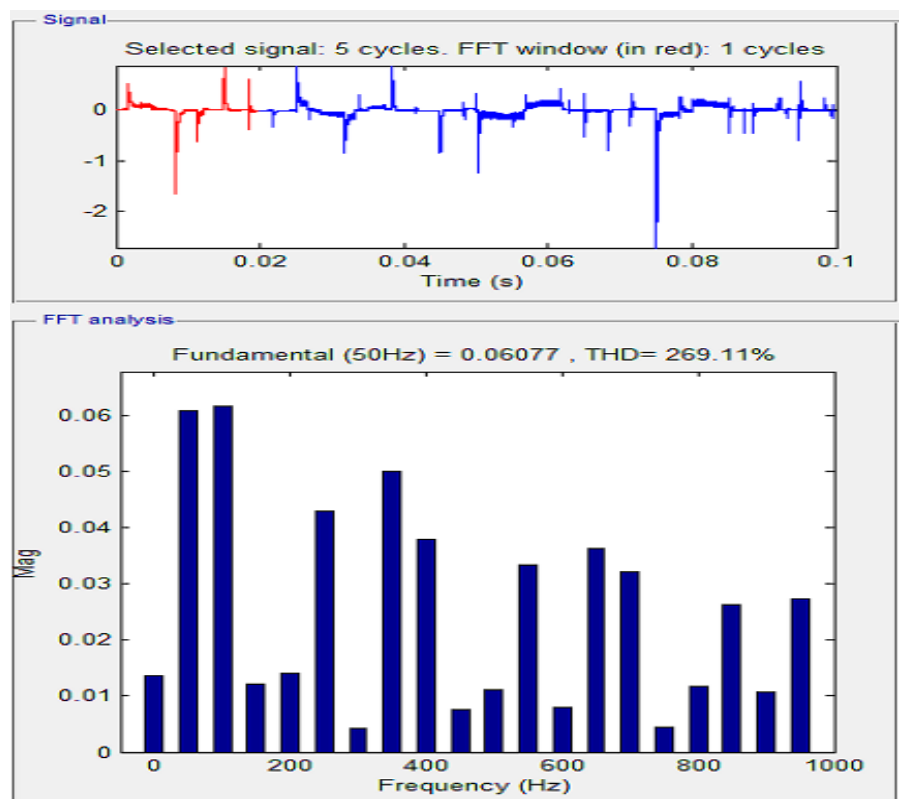

Fig. 31. FFT analysis of fixed output $50 \mathrm{~Hz}$ with $20 \mathrm{~Hz}$ input signal
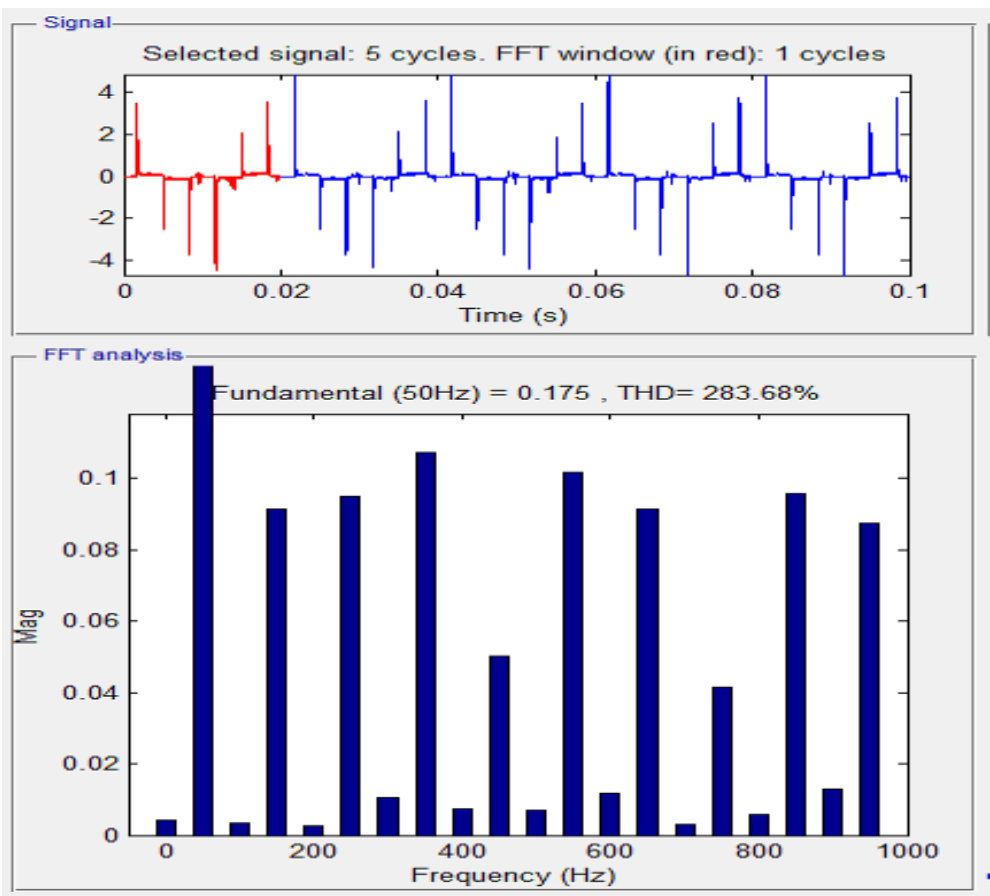

Fig. 32. FFT analysis of fixed output $50 \mathrm{~Hz}$ with $50 \mathrm{~Hz}$ input signal 


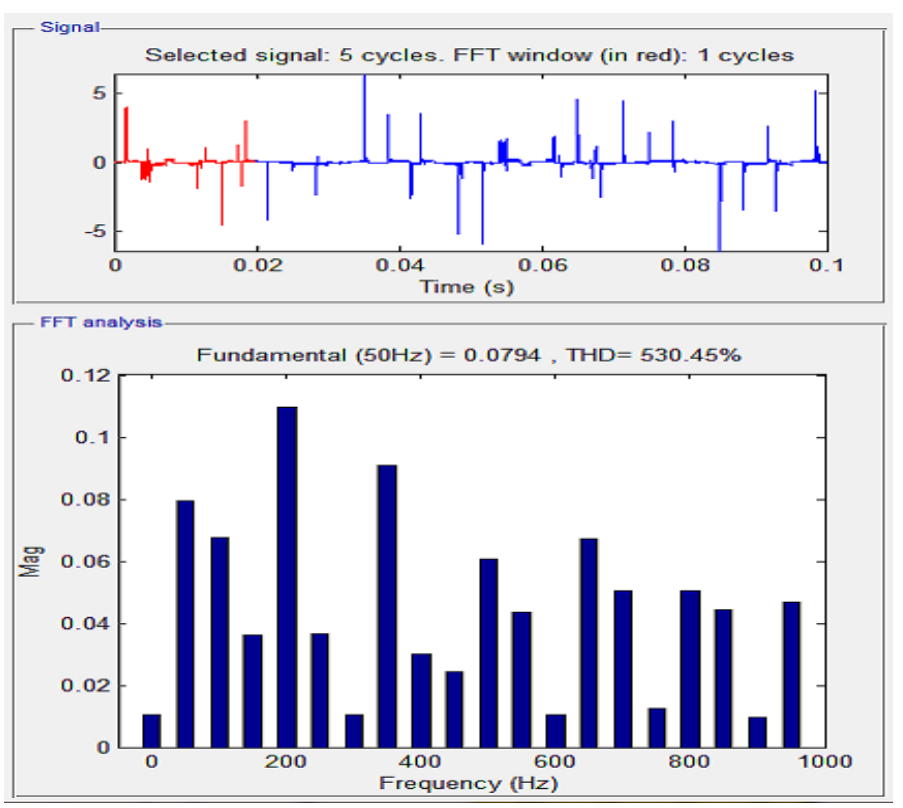

Fig. 33. FFT analysis of fixed output $50 \mathrm{~Hz}$ with $70 \mathrm{~Hz}$ input signal
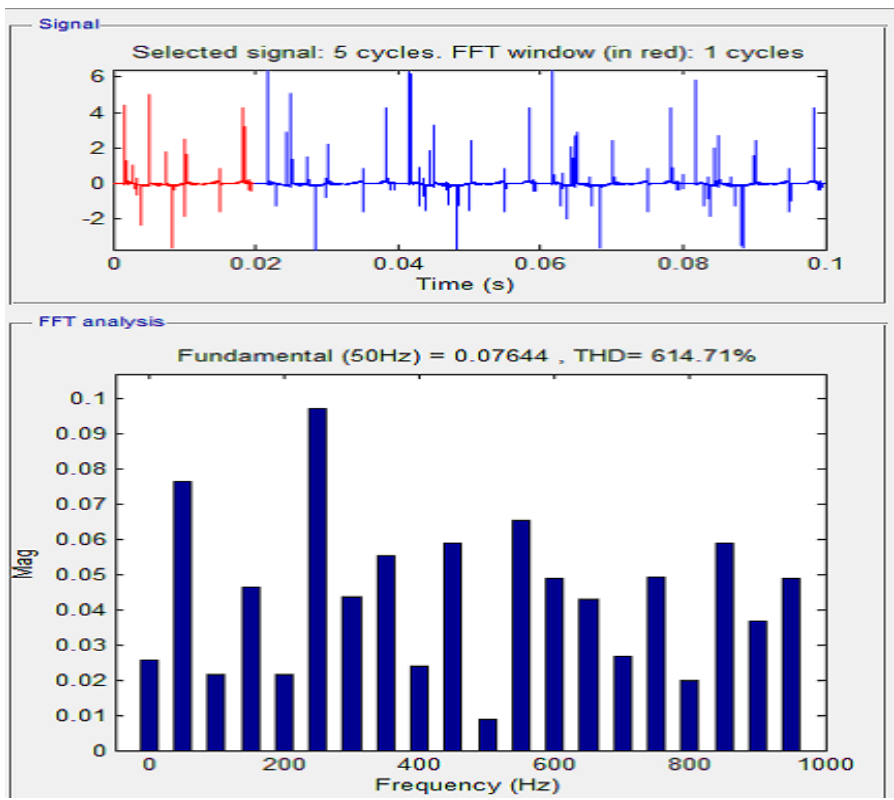

Fig. 34. FFT analysis of fixed output $50 \mathrm{~Hz}$ with $100 \mathrm{~Hz}$ input signal

\section{CONCLUSION}

The designed model of pulse width modulation based matrix converter is simulated on Matlab. It is verified from simulation that the objectives of maximizing voltage transfer ratio and minimization of harmonics are achieved. Any desired output voltage can be achieved irrespective of input voltage with much reduced harmonics. Changes in input voltage due to 
unwanted reasons or due to faults in the power generating equipments do not affect the load. In other words, this model provides an isolation between the in input and output. Changes in output voltages due to faults in the loads and deterioration of insulation do not affect the source voltages when connected via this model. Hence, the other loads connected to this source voltage are not affected. Further, this model provides low harmonic contents and any desired frequency can be achieved at the output side irrespective of input frequency with less harmonics. This objective helps to connect the variable frequency and variable speed drives via this model. Changes in the input frequency due to loss of synchronism time and again do not affect the loads as this model has the ability to not to transfer the input frequency changes at the output side. In-short, this designed model will revolutionize the implementation of matrix converters to fields of variable frequency drives, efficient controlling of power sources and loads, synchronization, insulation coordination, electric arc furnaces and welding.

\section{COMPETING INTERESTS}

Authors have declared that no competing interests exist.

\section{References}

[1] Mahmoud A. Sayed, Atif lqbal. Pulse width modulation technique for a three-tofive phase matrix converter with reduced commutations. IEEE IET Power Electronics. 2016;9(3):466-475.

[2] Vengadeshwaran Velu, Norman Mariun, Mohd Amran Mohd Radzi, Nashiren Farzilah Mailah. Equalization technique for balancing the modulation ratio characteristics of the single-phase-to-threephase matrix converter. Hindawi Journal of Scientific Programming. 2016;1-10.

[3] Wei L, Lipo TA, Chan H. Matrix converter topologies with reduced number of switches. Blacksburg, USA. 2002;125-130.

[4] Schafmeister F. Sparse and indirect matrix converter. PhD thesis, ETH Zrich, Switzerland; 2007.
[5] Round SD, Kolar JW, Schafmeister F, Ertl $H$. Three phase ac to ac sparse matrix converter. Transactions Power Electronics. 2007;22(5):1649-1661.

[6] Kolar JW. Vorrichtung zur quasi direkten pulsbreitengesteuerter energieunformung zwischen dreiphasennetzen; 2001.

[7] Krishnan R, Kazmierkowski MP, Blaabjerg F. Control in Power Electronics: Selected Problems. PhD thesis, San Diego; 2002.

[8] Raheel Muzzammel, Umair Tahir. Comprehensive comparison of pwm and svm based three phase ac to ac matrix converters. Automatic Control and System Engineering Journal. 2016;16(2):43-57.

[9] Stork M, Hammerbauer J. Variable frequency pulse width modulation. Proceedings of the 10th International Conference of Measurement. Smolenice, Slovakia. 2015;43-46.

[10] Raheel Muzzammel, Muhammad Saeed Akhtar Khan. Detailed harmonic analysis for pulse width modulation based ac to ac matrix converter. International Journal of Multidisciplinary Sciences and Engineering. 2017;8(2).

[11] Doval-Gandoy J, Lopez O, Alvarez J, Freijedo FD. Multilevel multiphase space vector pwm algorithm. IEEE transactions on Industrial Electronics. 2008;55(5):244-251.

[12] Moynihan JF, Egan MG, Murphy JMD. Theoretical spectra of space vector modulated waveforms. IEEE proceedings of Electrical Power Applications. 1998;145(1).

[13] Arrillaga J, Watson N. Power system harmonics. Wiley, New York; 2003.

[14] Paice D. Power electronic converter harmonics. Chapter Multiple Methods for Clean Power. IEEE Press, $2{ }^{n d}$ edition; 1996.

[15] Recommended practices and requirements for harmonics control in electrical power systems. IEEE. 1993;519.

[16] Limits for harmonic current emission (equipment input current 16 a per phase). IEC $1000-3-2$ International Standard; 1995. 
[17] Limits for harmonic current emission (equipment input current up to and including 16 a per phase). IEC 610003-2 International Standard; 2000.

[18] Akagi H, Tsukamoto $Y$, Nabae A. Analysis and design of an active power filter quadseries voltage source pwm converters. IEEE Trans. Ind. Electron. 1990;26(1):93-98.

[19] Akagi H, Peng FZ, Nabae A. A new approach to harmonic compensation in power system: A combines system of shunt passive and series active filters. IEEE Trans. Ind. Electron. 1990;26(6):983-990.

[20] Akagi $H$, Fujita $H$. New power line conditioner for harmonic compensation in power systems. IEEE Trans. Power Del. 1995;10(3):1570-1575.

[21] Jones V, Bose B. A frequency step-up cyclo converter using power transistors in inverseseries mode. Int. Journal Electronics. 1976;41(6):573-587.

[22] Venturini M. A new sine wave in sine wave out, conversion technique which eliminates reactive elements. In: Proc. POWERCON 7. 1980;E301-E315.

[23] Venturini M, Alesina A. The generalized transformer: A new bidirectional sinusoidal waveform frequency converter with continuously adjustable input power factor.In: Conf. Rec. IEEE PESC80. 1980;242-252.

[24] Rodriguez J. A new control technique for ac-ac converters. IFAC Control in Power Electronics and Electrical Drives. 1983;203208.

[25] Oyama J, Higuchi T, Yamada E. New control strategy for matrix converter. In: Conf. Rec. IEEE PESC89. 1989;360-367.

[26] Braun M, Hasse K. A direct frequency changer with control of input reactive power. IFAC Control in Power Electronics and Electrical Drives. 1983;187-194.

[27] Kastner G, Rodriguez J. A forced commutated cyclo converter with control of the source and load currents. Proc. EPE85. 1985;1141-1146.

[28] Borojevic D, Huber L, Burany N. Voltage space vector based pwm control of forced commutated cyclo convertors. IEEE IECON. 1989;106-111.

[29] Neft CL, Schauder CD. Theory and design of a 30-hp matrix converter. IEEE Trans. Ind. Applicat. 1992;28(3):546-551.

(C) 2017 Muzzammel and Tahir; This is an Open Access article distributed under the terms of the Creative Commons Attribution License (http://creativecommons.org/licenses/by/4.0), which permits unrestricted use, distribution, and reproduction in any medium, provided the original work is properly cited. 